\title{
Neurovascular Unit Dysfunction and Neurodegenerative Disorders
}

\author{
Xing Yu't, Caihong $\mathrm{Ji}^{2+}$ and Anwen Shao ${ }^{3 *}$ \\ ${ }^{1}$ Department of Surgery, The Second Affiliated Hospital, Zhejiang University School of Medicine, Hangzhou, China, \\ ${ }^{2}$ Department of Neurology, The First Affiliated Hospital, Zhejiang University School of Medicine, Hangzhou, China, \\ ${ }^{3}$ Department of Neurosurgery, The Second Affiliated Hospital, Zhejiang University School of Medicine, Hangzhou, China
}

OPEN ACCESS

Edited by:

Naoko Kaneko,

Nagoya City University, Japan

Reviewed by:

Nigel Hooper,

University of Manchester

United Kingdom

Miquel Vila,

Vall d'Hebron Research Institute

(NHIR), Spain

${ }^{*}$ Correspondence:

Anwen Shao

21118116@zju.edu.cn;

anwenshao@sina.com

tThese authors have contributed

equally to this work

Specialty section:

This article was submitted to

Neurodegeneration,

a section of the journal

Frontiers in Neuroscience

Received: 12 February 2020

Accepted: 20 March 2020

Published: 29 April 2020

Citation:

Yu X, Ji C and Shao A (2020) Neurovascular Unit Dysfunction and Neurodegenerative Disorders.

Front. Neurosci. 14:334.

doi: 10.3389/fnins.2020.00334
The neurovascular unit (NVU), composed of vascular cells, glial cells, and neurons, is the minimal functional unit of the brain. The NVU maintains integrity of the bloodbrain barrier (BBB) and regulates supply of the cerebral blood flow (CBF), both of which are keys to maintaining normal brain function. BBB dysfunction and a decreased CBF are early pathophysiological changes in neurodegenerative disorders, such as Alzheimer's disease (AD), Parkinson's disease (PD), and amyotrophic lateral sclerosis (ALS). In this review, we primarily focus on the NVU in AD as much research has been performed on the connection between NVU dysfunction and AD. We also discuss the role of NVU dysfunction in the pathophysiological mechanisms of PD and ALS. As most neurodegenerative diseases are difficult to treat, we discuss several potential drug targets that focus on the NVU that may inform novel vascular-targeted therapies for AD, PD, and ALS.

Keywords: Alzheimer's disease, blood-brain barrier, neurovascular unit, neurodegenerative disease, target

\section{INTRODUCTION}

Neurodegenerative disorders, like Alzheimer's disease (AD), Parkinson's disease (PD), and amyotrophic lateral sclerosis (ALS), are severe neurological disorders that severely affect the quality of life of patients and result in a heavy burden on the economy and society. AD symptoms include memory loss and cognitive impairment (Govindpani et al., 2019). The prevalence of AD patients is high. In 2020, there were approximately 4.7 million people with AD in the United States, and by 2050, the number is expected to triple (Hebert et al., 2013). PD is the second most common neurodegenerative disorder. Common clinical manifestations include tremor, rigidity, and bradykinesia, which result in a heavy burden on patients and society (Lee and Pienaar, 2014). ALS is a common degenerative disease, which affects motor neurons and causes progressive atrophy of skeletal muscles, paralysis, and death (Petrov et al., 2017). However, our understanding of the pathogenesis of these disorders is still limited.

Numerous research studies have demonstrated that the diseases mentioned above are related to disruption of the neurovascular unit (NVU) (Sweeney et al., 2018; Liu et al., 2019). The NVU, which is composed of vascular cells, glial cells, and neurons, plays an important role in maintaining the functional integrity of the blood-brain barrier $(\mathrm{BBB})$ and regulating the volume of the cerebral blood flow (CBF) (Sweeney et al., 2018). Disruption of the NVU may induce dysfunction of the BBB and decrease the $\mathrm{CBF}$, which may contribute to the pathogenesis of neurodegenerative disorders. When the NVU is disrupted and CBF decreases, not only is the supply of oxygen and nutrients 
to the brain reduced but also the clearance of neurotoxic substance, such as $\beta$-amyloid $(\mathrm{A} \beta)$ and $\alpha$-synuclein from brain parenchyma is diminished.

In this review, we will discuss the roles of the NVU in the pathogenesis of neurodegenerative diseases, $\mathrm{AD}, \mathrm{PD}$, and ALS. Because the prevalence of Huntington's disease, multiple sclerosis, and other neurodegenerative diseases is relatively low (McColgan and Tabrizi, 2018), we do not discuss research related to those diseases in this review. We will especially focus on $\mathrm{AD}$ because of significant research related to the close interaction between NVU dysfunction and AD. In this article, we describe the composition of the NVU as well as its function in molecular transport and $\mathrm{CBF}$ regulation. Moreover, in this study, we review changes in the NVU with respect to the pathogenesis of neurodegenerative disorders, including specific mechanisms in different neurodegenerative diseases. Finally, we review potential therapeutic targets associated with these neurovascular deficits.

\section{COMPOSITION OF THE NEUROVASCULAR UNIT}

The NVU is composed of vascular cells (including endothelial cells, pericytes, and vascular smooth muscle cells), glial cells (astrocytes, microglia, and oligodendroglia), and neurons (Figure 1; Zlokovic, 2011). The tube structure of the capillaries in the brain is formed by endothelial cells. The outside of the endothelial tubes is surrounded by pericytes and astrocyte endfeet. Moreover, endothelial tubes are surrounded by extracellular matrix that forms the basement membrane. Combined with neurons, all those mentioned above comprise the NVU. Tight junctions and adherens junctions connect endothelial cells and tight junctions limit the paracellular permeability of the BBB (Zlokovic, 2008). There are several transmembrane proteins involved in constructing tight junctions, including claudin, occludin, junctional adhesion molecule, and zonula occludens-1 (ZO-1) (Zlokovic, 2011; Yamazaki and Kanekiyo, 2017). Vascular endothelial (VE) cadherin is the principal cadherin that forms the adherens junction and mediates intercellular adhesion (Zenaro et al., 2017). Both tight and adherens junctions play key roles in the control of endothelial permeability. Tight junctions prevent free diffusion of proteins and seal the paracellular cleft between endothelial cells (Tietz and Engelhardt, 2015), whereas adherens junctions play a key role in cell-to-cell contacts and promote cell maturation (Tietz and Engelhardt, 2015).

Pericytes cover the abluminal surface of capillaries and regulate blood flow by controlling the capillary diameter (Hamilton et al., 2010; Winkler et al., 2011). Pericytes also clear toxic proteins to maintain the stability of the central nervous system (CNS) and play a key role in the formation of tight junctions (Daneman et al., 2010; Sagare et al., 2013).

Astrocytes are the most abundant glial cells in CNS. In the NVU, astrocytes communicate with endothelial cells through their end-feet (Abbott et al., 2006). Astrocytes combine neuronal activity with blood vessels in a process, termed neurovascular coupling. They respond to neuronal activity and deliver signals to regulate the CBF (Attwell et al., 2010; Gordon et al., 2011).
Furthermore, astrocytes play a vital role in molecular transport and BBB integrity (Yamazaki and Kanekiyo, 2017).

The NVU is crucial for stabilizing the environment of the brain. Firstly, the continuous endothelial cells with tight junction, basement membrane, and end-feet of astrocytes in the NVU form the $\mathrm{BBB}$. The $\mathrm{BBB}$ regulates which molecules or cells enter the brain and clear detrimental proteins from brain parenchyma to the peripheral circulatory system (Yamazaki and Kanekiyo, 2017). Secondly, the NVU regulates the CBF in response to neuronal activity through neurovascular coupling, which ensures sufficient oxygen and nutrient delivery to brain tissue where they are needed (Sweeney et al., 2018).

\section{NEUROVASCULAR UNIT DYSREGULATION IN ALZHEIMER'S DISEASE}

The most widely accepted pathophysiologic mechanism of $\mathrm{AD}$ is insoluble $A \beta$ deposition in senile plaques (Vinters, 2015). A $\beta$ accumulation in the brain is highly related to the dysfunction of the NVU (Sweeney et al., 2018) and is thought to be caused by the following two mechanisms, increased permeability of the BBB and reduced $\mathrm{CBF}$.

\section{Increased Permeability of the Blood-Brain Barrier}

As mentioned above, adjacent endothelial cells are connected by tight and adherens junctions, which form the $\mathrm{BBB}$ to maintain homeostasis of the brain. Various studies using different experimental methods have shown that the $\mathrm{BBB}$ integrity is impaired in AD (Yamazaki and Kanekiyo, 2017).

The detection of plasma-derived proteins in brain parenchyma is an extensively used approach for detecting BBB breakdown. Plasma proteins, including prothrombin, are found in postmortem cortical tissues of $\mathrm{AD}$ patients, and leakage of proteins is more common in patients with at least one APOE4 allele (Zipser et al., 2007). Using a novel dynamic contrast-enhanced MRI protocol to quantify BBB permeability, Montagne et al. (2015) showed that BBB permeability was increased in patients with mild impaired cognitive function than in healthy controls. Furthermore, BBB dysfunction leads to decreased A $\beta$ clearance in AD (Govindpani et al., 2019). There are several mechanisms related to BBB dysfunction, which may lead to amyloid burden in the brain (Figure 2).

Firstly, decreased expression of low-density lipoprotein receptor-related protein 1 (LRP1) and P-glycoprotein (P-gp), together with increased expression of the receptor for advanced glycation end products (RAGE), is are observed in endothelial cells in AD patients (Yamazaki and Kanekiyo, 2017; Zenaro et al., 2017). All these proteins are crucial in $A \beta$ transport across the BBB. LRP1 is expressed on endothelial cells and can internalize $\mathrm{A} \beta$ on the abluminal side (Cupino and Zabel, 2014; Yamazaki and Kanekiyo, 2017; Goulay et al., 2019). The internalized $A \beta$ is then transported into lysosome in endothelial cells for further degradation, and some internalized 


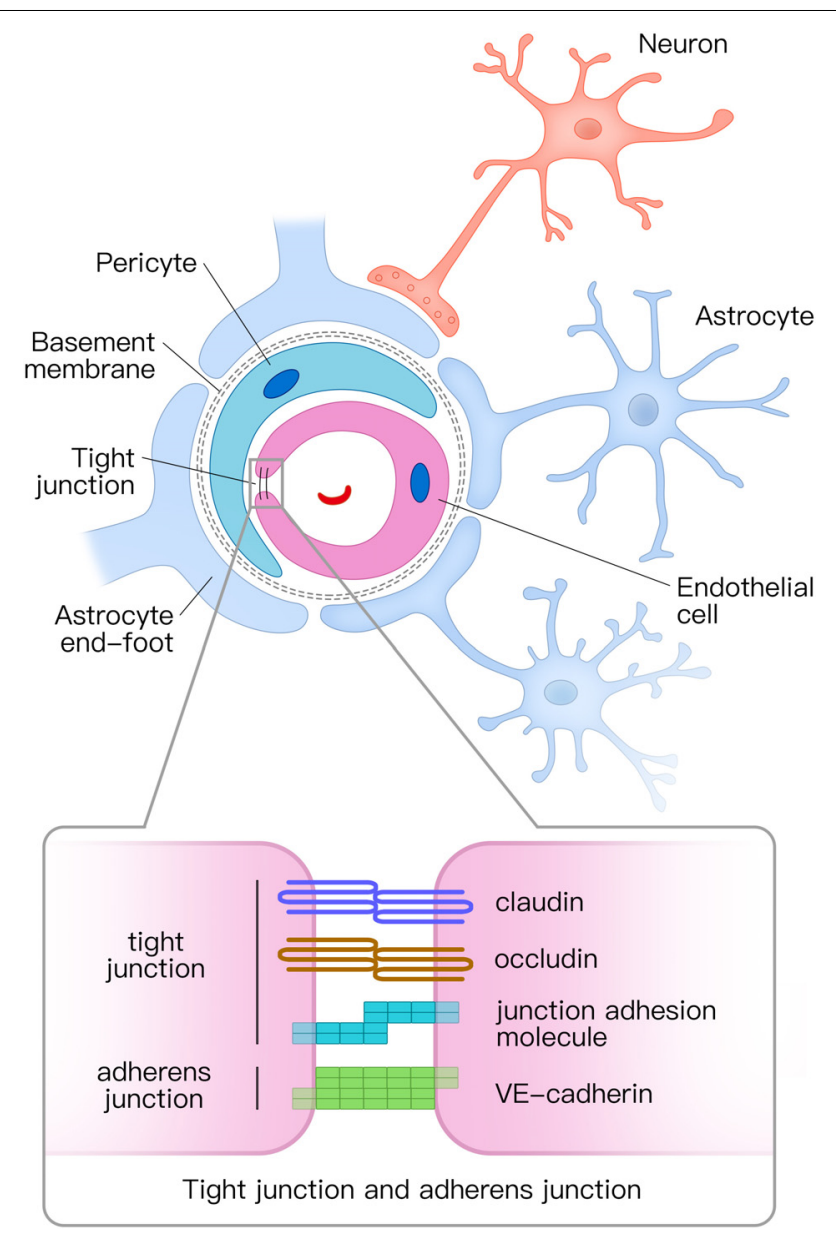

FIGURE 1 | Structural diagram of the neurovascular unit (NVU) and the composition of tight junctions and adherens junctions. The NVU is composed of vascular cells (including endothelial cells, pericytes, and vascular smooth muscle cells), glial cells (astrocytes, microglia, and oligodendroglia), and neurons. Pericytes and astrocyte end-feet surround endothelial tubes. Adjacent endothelial cells are connected by tight junctions and adherens junctions. The tight junction is mainly composed of claudin, occludin, and junctional adhesion molecules, whereas the adherens junction is composed of vascular endothelial (VE) cadherin. NVU, neurovascular unit.

$\mathrm{A} \beta$ would be transferred to the luminal side by receptormediated transcytosis (Pflanzner et al., 2011; Candela et al., 2015). P-gp is an ATP-dependent efflux transporter that is located on the luminal surface of endothelial cells (Schinkel, 1999). In a previous animal study, it was concluded that deficient expression of $\mathrm{P}-\mathrm{gp}$ decreased $\mathrm{A} \beta$ clearance and increased $\mathrm{A} \beta$ deposition in the brain (Cirrito et al., 2005). RAGE is a member of immunoglobulin superfamily and can bind $A \beta$ (Yan et al., 2010). RAGE mediates the entry of $A \beta$ from peripheral vessels to the brain through the BBB. RAGE immunoreactivity in endothelial cells was significantly increased in postmortem AD brains compared with healthy controls (Miller et al., 2008). Increased expression of RAGE in endothelial cells leads to more influx of $A \beta$ from the peripheral circulatory system to brain parenchyma.
Secondly, tight junction proteins such as occludins, claudins, and ZO-1 are reduced in endothelial cells (Marco and Skaper, 2006; Kook et al., 2012; Wan et al., 2015). As reported in previous studies, $A \beta$ was responsible for changes in tight junction protein expression (Marco and Skaper, 2006; Kook et al., 2012; Wan et al., 2015). It has been revealed that $A \beta 1-42$ oligomers disrupt tight junctions and increase permeability of the $\mathrm{BBB}$ through reduction in the expression of occludin, claudin-5, and ZO-1 in endothelial cells (Kook et al., 2012; Wan et al., 2015).

\section{Cerebral Blood Flow Reduction}

Decades before the onset of clinical symptoms, CBF in the cortex changed in AD patients (Binnewijzend et al., 2016; Hays et al., 2016; Dong et al., 2018). In AD and mild cognitive impairment patients, arterial spin-labeling MRI demonstrated reduced CBF in temporal and parietal cortices (Schuff et al., 2009; Alexopoulos et al., 2012).

The most widely accepted cause of CBF reduction in $\mathrm{AD}$ is the cholinergic-vascular hypothesis (Govindpani et al., 2019). This hypothesis postulates that CBF changes are due to changes in vascular innervation caused by neuronal loss, especially the loss of cholinergic innervation. In a previous study, an extensive reduction in cholinergic neurons in the temporal lobe cortex and hippocampus of postmortem $\mathrm{AD}$ brains was shown (Babic, 1999). Cholinergic neurons have a critical role in controlling the vascular tone in the brain (Van Beek and Claassen, 2011). Acetylcholine binding to muscarinic receptors in vascular smooth muscle cells dilates arterioles (Hamel, 2004). The deficit in neurovascular coupling leads to decreased CBF in the brain.

In addition to disruption of neurovascular coupling, vascular abnormalities may lead to decreased CBF in AD (De La Torre, 1997). Vascular abnormalities, such as tortuous, kinking, looping, or twisting arterioles, are common in $\mathrm{AD}$ (Baloyannis and Baloyannis, 2012). Such morphological changes in arterioles are due to vessel wall thinning and vascular smooth muscle cells loss. String vessels, which are composed of connective tissue and lack endothelial cells, are not functional in maintaining BBB integrity. The density of string vessels is remarkably increased in the brain gray matter of AD patients (Hunter et al., 2012), and this is related to decreased $\mathrm{CBF}$ in the brain.

A decreased $\mathrm{CBF}$ also decreases clearance and increases the deposition of A $\beta$ (Mosconi, 2005; Mawuenyega et al., 2010). It has been reported that parenchymal $A \beta$ deposition and cerebral amyloid angiopathy burden are increased in animal models of cerebral hypoperfusion (Garcia-Alloza et al., 2011; Okamoto et al., 2012; Li et al., 2014; Gupta and Iadecola, 2015). Consistent with the data from animal experiments, postmortem human brains showed that the severity of cerebral amyloid angiopathy significantly correlated to cortical microinfarcts (Okamoto et al., 2012). Similar to the role of hypoperfusion in promoting $A \beta$ accumulation, it has been reported that plasma $\mathrm{A} \beta$ increased after cardiac arrest in humans (Zetterberg et al., 2011). Hypoperfusion can trigger accelerated deposition of $A \beta$ (Garcia-Alloza et al., 2011). Hypoperfusion in the brain has been shown to dramatically increase the cleavage of $A \beta$ from the amyloid precursor protein (APP), through upregulation of $\beta$ - and $\gamma$-secretase, two enzymes that are required for the production of 


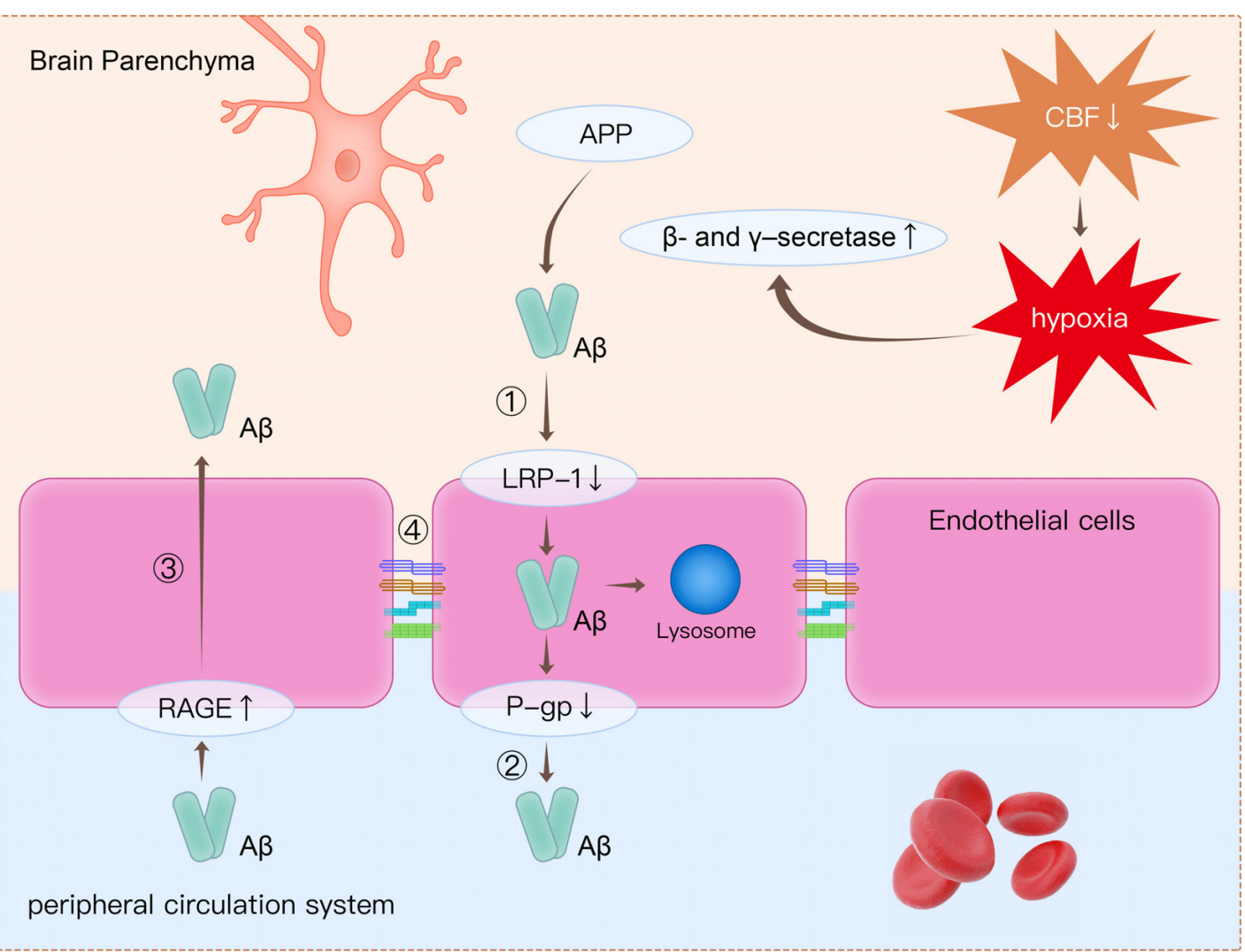

FIGURE 2 | Clearance of $\beta$-amyloid (A $\beta$ ) from the brain is impaired through several mechanisms. (1) Decreased expression of LRP1 on endothelial cells causes decreased transport of $A \beta$ from the brain to the peripheral circulatory system. (2) P-gp is an ATP-dependent efflux transporter that is expressed in the luminal surface of endothelial cells. Deficient expression of P-gp decreases A $\beta$ clearance. (3) RAGE is an immunoglobulin superfamily member and a receptor for A $\beta$. Increased expression of RAGE in endothelial cells leads to more influx of $A \beta$ from the peripheral circulatory system to brain parenchyma. (4) Tight junction proteins such as occludin, claudins, and ZO-1 are reduced in endothelial cells, thereby leading to impairment of BBB integrity. Apart from disruption of the BBB, decreased CBF leads to hypoxia, which upregulates the production of $\beta$ - and $\gamma$-secretase. Increased $\beta$ - and $\gamma$-secretase increases the cleavage of A $\beta$ from APP. LRP1, low-density lipoprotein receptor-related protein 1; P-gp, P-glycoprotein; RAGE, receptor for advanced glycation end products; ZO-1, zonula occludens-1; BBB, blood-brain barrier; $\mathrm{CBF}$, cerebral blood flow; APP, amyloid precursor protein.

A $\beta$ (Zhang et al., 2007; Li et al., 2009). Moreover, in addition to increased production of $A \beta$, decreased CBF leads to insufficient clearance of $A \beta$. It was found that about half of the $A \beta$ clearance could be attributed to CBF and vascular-perivascular pathways (Roberts et al., 2014).

The effects of brain hypoxia and $A \beta$ deposition are mutual (Gupta and Iadecola, 2015). The accumulation of A $\beta$ deteriorates cerebrovascular function, increases arterial vasoconstriction, and reduces CBF (Thomas et al., 1996; Niwa et al., 2000).

\section{NEUROVASCULAR UNIT DYSREGULATION IN PARKINSON'S DISEASE}

The widely accepted pathological mechanism of PD involves the loss of dopaminergic neurons in the ventral tier mesencephalon (Lee and Pienaar, 2014). However, it is demonstrated that PD pathology not only is restricted to the dopaminergic system but also influences the noradrenergic, serotonergic, and cholinergic systems (Loane et al., 2013; Pienaar and Van De Berg, 2013). Increasing evidence has shown that disruption of the $\mathrm{BBB}$ may play a critical role in the pathological mechanism of $\mathrm{PD}$.

Previous research has revealed that the $\mathrm{BBB}$ is disrupted in various toxin-induced PD models, including 6-OHDA and MPTP-treated mice (Carvey et al., 2005; Chen et al., 2008). Other studies have demonstrated that the expression of $\alpha$-synuclein is associated with increased permeability of the BBB (Jangula and Murphy, 2013). Several mechanisms can explain the BBB disruption in PD patients. Firstly, with increasing age, senile astrocytes and microglia produce various cytokines, chemokines (e.g., IL-6, IL-1 $\beta$, and TNF- $\alpha$ ), and reactive oxygen species (ROS), which disrupt the integrity of the $\mathrm{BBB}$ and lead to the rearrangement of tight junctions (Collins et al., 2012). Secondly, PD patients show reduced expression of P-gp in the midbrain, which is related to $\mathrm{BBB}$ dysfunction (Kortekaas et al., 2005). It is thought that the decreased P-gp maybe related to an accumulation of $\alpha$-synuclein and other neurotoxic substances in the brain (Bartels, 2011). Decreased efflux membrane transport through P-gp leads to brain damage due 
to the accumulation of harmful substances. Furthermore, in PD patients, angiogenesis occurs; however, the newly created vessels are less likely to display the restrictive properties of the BBB. Hence, the poorly developed $\mathrm{BBB}$ cannot protect the parenchyma from toxic factors in the peripheral circulation (Desai Bradaric et al., 2012).

\section{NEUROVASCULAR UNIT DYSREGULATION IN AMYOTROPHIC LATERAL SCLEROSIS}

Amyotrophic lateral sclerosis is a lethal neurological disease involving rapid and progressive degeneration of motor neurons in the brain and spinal cord. Most patients die within 24-48 months after symptom onset (Petrov et al., 2017). A small number of ALS patients have familial ALS, and of those, with a familial etiology, 20\% have inherited superoxide dismutase-1 (SOD1) mutations, which induce the disease (Garbuzova-Davis et al., 2011). For sporadic ALS, various pathological mechanisms have been proposed; however, the precise pathogenesis is still unclear. One widely accepted pathogenic mechanism of ALS is related to BBB and bloodspinal cord barrier (BSCB) impairment, which leads to motor neuron damage.

Mice with ALS-linked SOD1 mutations have reduced levels of tight junction proteins, including ZO-1, occludin, and claudin5, which disrupt the BBB and BSCB functions (Zhong et al., 2008). Human lumbar spinal cords from ALS patients also demonstrate diminished expression of ZO-1 and occludin, which corresponds with the finding in animals (Henkel et al., 2009). Another study showed dramatically reduced perivascular occludin, collagen IV, and astrocyte end-feet surrounded with endothelial cells in the postmortem spinal cord of ALS patients (Miyazaki et al., 2011). Furthermore, the disruption of the BBB and BSCB occurs prior to motor neuron degeneration (Zhong et al., 2008). In the NVU, the degeneration of tight junctions, impairment of endothelial cells, and reduction in astrocytic endfeet contribute to dysfunction of the BBB and BSCB. This leads to vascular leakage and the entry of harmful substances from the peripheral blood into the CNS parenchyma (GarbuzovaDavis et al., 2008). The expression of two proteins important for endothelial cell function, GLUT-1 and CD146, is decreased in ALS (Garbuzova-Davis et al., 2007). Additionally, in SOD1 mutated mice, blood flow in the cervical and lumbar spinal cord is decreased by about $30-45 \%$ before the onset of symptoms (Zhong et al., 2008).

In short, the NVU is impaired in ALS before the onset of clinical symptoms, and damage to the NVU plays a key role in the pathogenesis of ALS (Garbuzova-Davis et al., 2011).

\section{IMPLICATIONS FOR DRUG TARGETS}

Increasing evidence has shown the important role of the NVU in the pathogenesis of neurodegenerative diseases, including AD, PD, and ALS (Sweeney et al., 2018). Most of these neurodegenerative disorders are intractable, especially $\mathrm{AD}$ and ALS. Therefore, looking to vascular cells as potential drug targets for neurodegenerative disorders is a promising avenue of research.

For instance, $\mathrm{BBB}$ breakdown and $\mathrm{CBF}$ reductions are critical in the pathogenesis of $\mathrm{AD}$. As discussed before, downregulation of LRP1 expression is found in endothelial cells and pericytes of $\mathrm{AD}$ patients, and this significantly affects the clearance of $A \beta$ across the $B B B$. Thus, increasing expression of LRP1 may be a promising therapeutic target for $\mathrm{AD}$ patients. Statins can reduce the risk of $\mathrm{AD}$ by decreasing $\mathrm{A} \beta$ levels. In addition, the molecular mechanism of how statins influence $\mathrm{A} \beta$ metabolism involves increasing the expression of LRP1 and accelerating A $\beta$ clearance (Shinohara et al., 2010). Therefore, statins may be recommended for upregulation of LRP1 (Whitfield, 2007). Recent research has found that treatment with 1,25-(OH)2-vitamin D3 increased the expression of LRP1 significantly both in vivo and in vitro (Patel and Shah, 2017; Cai et al., 2018). Therefore, sufficient vitamin $\mathrm{D}$ supplementation may be beneficial for $A \beta$ clearance from the brain parenchyma to blood. Furthermore, loss of cholinergic innervation leads to decreased $\mathrm{CBF}$ in $\mathrm{AD}$ patients. Acetylcholinesterase inhibitors (AChEIs), like tacrine, galantamine, and donepezil, increase the acetylcholine concentrations and have been widely used for decades (Govindpani et al., 2019). AChEIs have been shown to increase blood perfusion in the frontal lobe and prevent the progression of cognitive impairment after 1 year of treatment (Shimizu et al., 2015).

For abnormal angiogenesis, $A \beta$ immunization therapy in Tg2576 mice has been shown to dramatically reduce the formation of non-functional vessels, which increase vascular permeability and lead to brain damage (Biron et al., 2013). In $\mathrm{A} \beta$-immunized mice, amyloidogenesis-triggered angiogenesis was decreased, and the vascular density reverted to normal levels. However, early clinical trials using the $A \beta$ vaccine in human $A D$ showed unexpected negative side effects. Therefore, additional studies are required prior to the application of $A \beta$ immunization therapy in AD patients (Masliah et al., 2005).

In a mouse model of $\mathrm{AD}$, implantation of encapsulated VE growth factor (VEGF)-secreting cells resulted in increased vascularization and reduced $\mathrm{A} \beta$ deposition in the cerebral cortex (Spuch et al., 2010). Furthermore, cognitive behavior improved after implantation of VEGF microcapsules (Spuch et al., 2010). A recent study in mice showed that the transplantation of endothelial progenitor cells into the hippocampus increased microvessel density, whereas the deposition of $A \beta$ senile plaque and hippocampal cell apoptosis was decreased (Zhang et al., 2018). Transplantation of endothelial progenitor cells could also upregulate the expression of the tight junction proteins ZO-1, occludin, and claudin-5 (Zhang et al., 2018).

Given that oxidative stress plays an important role in the underlying mechanism of PD, astrocytes as a part of NVU secrete several beneficial antioxidant compounds, including glutathione (GSH), superoxide dismutases (SODs), and ascorbate (Cabezas et al., 2014). These molecules are important for neuron survival during the neurodegenerative processes (Cabezas et al., 2014). 
Several studies have showed that GSH was critical for the protection of BBB integrity (Agarwal and Shukla, 1999). Thus, supplementary of these molecules may be an effective treatment for PD.

\section{CONCLUSION}

In this review, we describe the role of NVU dysfunction in the pathogenesis of several neurodegenerative diseases, including $\mathrm{AD}, \mathrm{PD}$, and $\mathrm{ALS}$. BBB breakdown and $\mathrm{CBF}$ reduction influence the removal of harmful substances from the brain and play an important role in the onset of neurodegenerative disorders. A focus on the NVU for potential drug targets may be helpful to inform novel vascular-targeted therapies. Nevertheless,

\section{REFERENCES}

Abbott, N. J., Ronnback, L., and Hansson, E. (2006). Astrocyte-endothelial interactions at the blood-brain barrier. Nat. Rev. Neurosci. 7, 41-53. doi: 10. $1038 / \mathrm{nrn} 1824$

Agarwal, R., and Shukla, G. S. (1999). Potential role of cerebral glutathione in the maintenance of blood-brain barrier integrity in rat. Neurochem. Res. 24, 1507-1514.

Alexopoulos, P., Sorg, C., Forschler, A., Grimmer, T., Skokou, M., Wohlschlager, A., et al. (2012). Perfusion abnormalities in mild cognitive impairment and mild dementia in Alzheimer's disease measured by pulsed arterial spin labeling MRI. Eur. Arch. Psychiatry Clin. Neurosci. 262, 69-77. doi: 10.1007/s00406-01 1-0226-2

Attwell, D., Buchan, A. M., Charpak, S., Lauritzen, M., Macvicar, B. A., and Newman, E. A. (2010). Glial and neuronal control of brain blood flow. Nature 468, 232-243. doi: 10.1038/nature09613

Babic, T. (1999). The cholinergic hypothesis of Alzheimer's disease: a review of progress. J. Neurol. Neurosurg. Psychiatry 67:558.

Baloyannis, S. J., and Baloyannis, I. S. (2012). The vascular factor in Alzheimer's disease: a study in Golgi technique and electron microscopy. J. Neurol. Sci. 322, 117-121. doi: 10.1016/j.jns.2012.07.010

Bartels, A. L. (2011). Blood-brain barrier P-glycoprotein function in neurodegenerative disease. Curr. Pharm. Des 17, 2771-2777. doi: $10.2174 / 138161211797440122$

Binnewijzend, M. A., Benedictus, M. R., Kuijer, J. P., Van Der Flier, W. M., Teunissen, C. E., Prins, N. D., et al. (2016). Cerebral perfusion in the predementia stages of Alzheimer's disease. Eur. Radiol. 26, 506-514. doi: 10. 1007/s00330-015-3834-9

Biron, K. E., Dickstein, D. L., Gopaul, R., Fenninger, F., and Jefferies, W. A. (2013). Cessation of neoangiogenesis in Alzheimer's disease follows amyloidbeta immunization. Sci. Rep. 3, 1354-1354.

Cabezas, R., Avila, M., Gonzalez, J., El-Bacha, R. S., Baez, E., Garcia-Segura, L. M., et al. (2014). Astrocytic modulation of blood brain barrier: perspectives on Parkinson's disease. Front. Cell Neurosci. 8:211. doi: 10.3389/fncel.2014. 00211

Cai, Z., Qiao, P.-F., Wan, C.-Q., Cai, M., Zhou, N.-K., and Li, Q. (2018). Role of Blood-Brain Barrier in Alzheimer's Disease. J. Alzheimer Dis. 63, 1223-1234.

Candela, P., Saint-Pol, J., Kuntz, M., Boucau, M. C., Lamartiniere, Y., Gosselet, F., et al. (2015). In vitro discrimination of the role of LRP1 at the BBB cellular level: focus on brain capillary endothelial cells and brain pericytes. Brain Res. 1594, 15-26. doi: 10.1016/j.brainres.2014.10.047

Carvey, P. M., Zhao, C. H., Hendey, B., Lum, H., Trachtenberg, J., Desai, B. S., et al. (2005). 6-Hydroxydopamine-induced alterations in blood-brain barrier permeability. Eur. J. Neurosci. 22, 1158-1168. doi: 10.1111/j.1460-9568.2005. 04281.x

Chen, X., Lan, X., Roche, I., Liu, R., and Geiger, J. D. (2008). Caffeine protects against MPTP-induced blood-brain barrier dysfunction in mouse striatum. J. Neurochem. 107, 1147-1157. the mechanisms of BBB breakdown during neurodegenerative diseases need to be further elucidated.

\section{AUTHOR CONTRIBUTIONS}

$\mathrm{XY}$ and CJ drafted the manuscript. AS reviewed and modified the manuscript. All authors agreed on the final version.

\section{FUNDING}

This work was funded by the National Natural Science Foundation of China (81701144) and Zhejiang Provincial Natural Science Foundation of China (LQ20H090018).

Cirrito, J. R., Deane, R., Fagan, A. M., Spinner, M. L., Parsadanian, M., Finn, M. B., et al. (2005). P-glycoprotein deficiency at the blood-brain barrier increases amyloid-beta deposition in an Alzheimer disease mouse model. J. Clin. Invest. 115, 3285-3290. doi: 10.1172/jci25247

Collins, L. M., Toulouse, A., Connor, T. J., and Nolan, Y. M. (2012). Contributions of central and systemic inflammation to the pathophysiology of Parkinson's disease. Neuropharmacology 62, 2154-2168. doi: 10.1016/j.neuropharm.2012. 01.028

Cupino, T. L., and Zabel, M. K. (2014). Alzheimer's silent partner: cerebral amyloid angiopathy. Translat. Stroke Res. 5, 330-337. doi: 10.1007/s12975-01 3-0309-7

Daneman, R., Zhou, L., Kebede, A. A., and Barres, B. A. (2010). Pericytes are required for blood-brain barrier integrity during embryogenesis. Nature 468, 562-566. doi: 10.1038/nature09513

De La Torre, J. C. (1997). Hemodynamic consequences of deformed microvessels in the brain in Alzheimer's disease. Ann. N. Y. Acad. Sci. 826, 75-91. doi: 10.1111/j.1749-6632.1997.tb48462.x

Desai Bradaric, B., Patel, A., Schneider, J. A., Carvey, P. M., and Hendey, B. (2012). Evidence for angiogenesis in Parkinson's disease, incidental Lewy body disease, and progressive supranuclear palsy. J. Neural Transm. 119, 59-71. doi: 10.1007/s00702-011-0684-8

Dong, S., Maniar, S., Manole, M. D., and Sun, D. (2018). Cerebral hypoperfusion and other shared brain pathologies in ischemic stroke and Alzheimer's Disease. Transl. Stroke Res. 9, 238-250. doi: 10.1007/s12975-01 7-0570-2

Garbuzova-Davis, S., Rodrigues, M. C., Hernandez-Ontiveros, D. G., Louis, M. K., Willing, A. E., Borlongan, C. V., et al. (2011). Amyotrophic lateral sclerosis: a neurovascular disease. Brain Res. 1398, 113-125.

Garbuzova-Davis, S., Saporta, S., Haller, E., Kolomey, I., Bennett, S. P., Potter, H., et al. (2007). Evidence of compromised blood-spinal cord barrier in early and late symptomatic SOD1 mice modeling ALS. PLoS One 2:e1205. doi: 10.1371/ journal.pone.0001205

Garbuzova-Davis, S., Saporta, S., and Sanberg, P. R. (2008). Implications of bloodbrain barrier disruption in ALS. Amyotrophic Lateral Scler. 9, 375-376. doi: $10.1080 / 17482960802160990$

Garcia-Alloza, M., Gregory, J., Kuchibhotla, K. V., Fine, S., Wei, Y., Ayata, C., et al. (2011). Cerebrovascular lesions induce transient $\beta$-amyloid deposition. Brain 134, 3697-3707. doi: 10.1093/brain/awr300

Gordon, G. R., Howarth, C., and Macvicar, B. A. (2011). Bidirectional control of arteriole diameter by astrocytes. Exp. Physiol. 96, 393-399. doi: 10.1113/ expphysiol.2010.053132

Goulay, R., Mena Romo, L., Hol, E. M., and Dijkhuizen, R. M. (2019). From stroke to dementia: a comprehensive review exposing tight interactions between stroke and Amyloid- $\beta$ formation. Translat. Stroke Res. doi: 10.1007/s12975019-00755-2 [Epub ahead of print].

Govindpani, K., Mcnamara, L. G., Smith, N. R., Vinnakota, C., Waldvogel, H. J., Faull, R. L., et al. (2019). Vascular dysfunction in alzheimer's disease: a prelude to the pathological process or a consequence of it? J. Clin. Med. 8:8050651. 
Gupta, A., and Iadecola, C. (2015). Impaired A $\beta$ clearance: a potential link between atherosclerosis and Alzheimer's disease. Front. Aging Neurosci. 7:115. doi: 10. 3389/fncel.2014.00115

Hamel, E. (2004). Cholinergic modulation of the cortical microvascular bed. Prog. Brain Res. 145, 171-178. doi: 10.1016/s0079-6123(03)45012-7

Hamilton, N. B., Attwell, D., and Hall, C. N. (2010). Pericyte-mediated regulation of capillary diameter: a component of neurovascular coupling in health and disease. Front. Neuroenerget. 2:5. doi: 10.3389/fnene.2010.00005

Hays, C. C., Zlatar, Z. Z., and Wierenga, C. E. (2016). The utility of cerebral blood flow as a biomarker of preclinical Alzheimer's Disease. Cell Mol. Neurobiol. 36, 167-179. doi: 10.1007/s10571-015-0261-z

Hebert, L. E., Weuve, J., Scherr, P. A., and Evans, D. A. (2013). Alzheimer disease in the United States (2010-2050) estimated using the 2010 census. Neurology 80 , 1778-1783. doi: 10.1212/wnl.0b013e31828726f5

Henkel, J. S., Beers, D. R., Wen, S., Bowser, R., and Appel, S. H. (2009). Decreased mRNA expression of tight junction proteins in lumbar spinal cords of patients with ALS. Neurology 72, 1614-1616. doi: 10.1212/wnl.0b013e3181a41228

Hunter, J. M., Kwan, J., Malek-Ahmadi, M., Maarouf, C. L., Kokjohn, T. A., Belden, C., et al. (2012). Morphological and pathological evolution of the brain microcirculation in aging and Alzheimer's disease. PLoS One 7:e036893. doi: 10.1371/journal.pone.00036893

Jangula, A., and Murphy, E. J. (2013). Lipopolysaccharide-induced blood brain barrier permeability is enhanced by alpha-synuclein expression. Neurosci. Lett. 551, 23-27. doi: 10.1016/j.neulet.2013.06.058

Kook, S. Y., Hong, H. S., Moon, M., Ha, C. M., Chang, S., and Mook-Jung, I. (2012). Abeta(1)(-)(4)(2)-RAGE interaction disrupts tight junctions of the blood-brain barrier via $\mathrm{Ca}(2)(+)$-calcineurin signaling. J. Neurosci. 32, 8845-8854. doi: 10. 1523/jneurosci.6102-11.2012

Kortekaas, R., Leenders, K. L., Van Oostrom, J. C. H., Vaalburg, W., Bart, J., Willemsen, A. T. M., et al. (2005). Blood-brain barrier dysfunction in parkinsonian midbrain in vivo. Ann. Neurol. 57, 176-179. doi: 10.1002/ana. 20369

Lee, H., and Pienaar, I. S. (2014). Disruption of the blood-brain barrier in Parkinson's disease: curse or route to a cure? Front. Biosci. 19:280. doi: 10.3389/ fnene. 2010.280

Li, H., Guo, Q., Inoue, T., Polito, V. A., Tabuchi, K., Hammer, R. E., et al. (2014). Vascular and parenchymal amyloid pathology in an Alzheimer disease knockin mouse model: interplay with cerebral blood flow. Mol. Neurodegen. 9:28. doi: $10.1186 / 1750-1326-9-28$

Li, L., Zhang, X., Yang, D., Luo, G., Chen, S., and Le, W. (2009). Hypoxia increases Abeta generation by altering beta- and gamma-cleavage of APP. Neurobiol. Aging 30, 1091-1098. doi: 10.1016/j.neurobiolaging.2007.10.011

Liu, X., Hou, D., Lin, F., Luo, J., Xie, J., Wang, Y., et al. (2019). The role of neurovascular unit damage in the occurrence and development of Alzheimer's disease. Rev. Neurosci. 30, 477-484. doi: 10.1515/revneuro-2018-0056

Loane, C., Wu, K., Bain, P., Brooks, D. J., Piccini, P., and Politis, M. (2013). Serotonergic loss in motor circuitries correlates with severity of action-postural tremor in PD. Neurology 80, 1850-1855. doi: 10.1212/wnl.0b013e318292a31d

Marco, S., and Skaper, S. D. (2006). Amyloid beta-peptide1-42 alters tight junction protein distribution and expression in brain microvessel endothelial cells. Neurosci. Lett. 401, 219-224. doi: 10.1016/j.neulet.2006.03.047

Masliah, E., Hansen, L., Adame, A., Crews, L., Bard, F., Lee, C., et al. (2005). Abeta vaccination effects on plaque pathology in the absence of encephalitis in Alzheimer disease. Neurology 64, 129-131. doi: 10.1212/01.wnl.0000148590. 39911.df

Mawuenyega, K. G., Sigurdson, W., Ovod, V., Munsell, L., Kasten, T., Morris, J. C., et al. (2010). Decreased clearance of CNS beta-amyloid in Alzheimer's disease. Science 330:1774. doi: 10.1126/science.1197623

McColgan, P., and Tabrizi, S. J. (2018). Huntington's disease: a clinical review. Eur. J. Neurol. 25, 24-34.

Miller, M. C., Tavares, R., Johanson, C. E., Hovanesian, V., Donahue, J. E., Gonzalez, L., et al. (2008). Hippocampal RAGE immunoreactivity in early and advanced Alzheimer's disease. Brain Res. 1230, 273-280. doi: 10.1016/j.brainres. 2008.06.124

Miyazaki, K., Ohta, Y., Nagai, M., Morimoto, N., Kurata, T., Takehisa, Y., et al. (2011). Disruption of neurovascular unit prior to motor neuron degeneration in amyotrophic lateral sclerosis. J. Neurosci. Res. 89, 718-728. doi: 10.1002/jnr. 22594
Montagne, A., Barnes, S. R., Sweeney, M. D., Halliday, M. R., Sagare, A. P., Zhao, Z., et al. (2015). Blood-brain barrier breakdown in the aging human hippocampus. Neuron 85, 296-302. doi: 10.1016/j.neuron.2014.12.032

Mosconi, L. (2005). Brain glucose metabolism in the early and specific diagnosis of Alzheimer's disease. FDG-PET studies in MCI and AD. Eur. J. Nucl. Med. Mol. Imaging 32, 486-510. doi: 10.1007/s00259-005-1762-7

Niwa, K., Carlson, G. A., and Iadecola, C. (2000). Exogenous A beta1-40 reproduces cerebrovascular alterations resulting from amyloid precursor protein overexpression in mice. J. Cereb. Blood Flow Metab. 20, 1659-1668. doi: 10.1097/00004647-200012000-00005

Okamoto, Y., Yamamoto, T., Kalaria, R. N., Senzaki, H., Maki, T., Hase, Y., et al. (2012). Cerebral hypoperfusion accelerates cerebral amyloid angiopathy and promotes cortical microinfarcts. Acta Neuropathol. 123, 381-394. doi: 10.1007/ s00401-011-0925-9

Patel, P., and Shah, J. (2017). Role of Vitamin D in Amyloid clearance via LRP1 upregulation in Alzheimer's disease: a potential therapeutic target? J. Chem. Neuroanat. 85, 36-42. doi: 10.1016/j.jchemneu.2017.06.007

Petrov, D., Mansfield, C., Moussy, A., and Hermine, O. (2017). ALS clinical trials review: 20 years of failure. are we any closer to registering a new treatment? Front. Aging Neurosci. 9:68. doi: 10.3389/fnagi.2017.00068

Pflanzner, T., Janko, M. C., Andre-Dohmen, B., Reuss, S., Weggen, S., Roebroek, A. J., et al. (2011). LRP1 mediates bidirectional transcytosis of amyloid-beta across the blood-brain barrier. Neurobiol. Aging 32, 2323-2311.

Pienaar, I. S., and Van De Berg, W. (2013). A non-cholinergic neuronal loss in the pedunculopontine nucleus of toxin-evoked parkinsonian rats. Exp. Neurol. 248, 213-223. doi: 10.1016/j.expneurol.2013.06.008

Roberts, K. F., Elbert, D. L., Kasten, T. P., Patterson, B. W., Sigurdson, W. C., Connors, R. E., et al. (2014). Amyloid- $\beta$ efflux from the central nervous system into the plasma. Ann. Neurol. 76, 837-844. doi: 10.1002/ana.24270

Sagare, A. P., Bell, R. D., Zhao, Z., Ma, Q., Winkler, E. A., Ramanathan, A., et al. (2013). Pericyte loss influences Alzheimer-like neurodegeneration in mice. Nat. Commun. 4, 2932-2932.

Schinkel, A. H. (1999). P-Glycoprotein, a gatekeeper in the blood-brain barrier. Adv. Drug Deliv. Rev. 36, 179-194. doi: 10.1016/s0169-409x(98) 00085-4

Schuff, N., Matsumoto, S., Kmiecik, J., Studholme, C., Du, A., Ezekiel, F., et al. (2009). Cerebral blood flow in ischemic vascular dementia and Alzheimer's disease, measured by arterial spin-labeling magnetic resonance imaging. Alzheimers Dement. 5, 454-462. doi: 10.1016/j.jalz.2009.04.1233

Shimizu, S., Kanetaka, H., Hirose, D., Sakurai, H., and Hanyu, H. (2015), Differential effects of acetylcholinesterase inhibitors on clinical responses and cerebral blood flow changes in patients with Alzheimer's disease: a 12-month, randomized, and open-label trial. Dement. Geriatr. Cogn. Disord. Extra 5, 135-146. doi: 10.1159/000375527

Shinohara, M., Sato, N., Kurinami, H., Takeuchi, D., Takeda, S., Shimamura, M., et al. (2010). Reduction of brain beta-amyloid (Abeta) by fluvastatin, a hydroxymethylglutaryl-CoA reductase inhibitor, through increase in degradation of amyloid precursor protein C-terminal fragments (APP-CTFs) and Abeta clearance. J. Biol. Chem. 285, 22091-22102. doi: 10.1074/jbc.m110. 102277

Spuch, C., Antequera, D., Portero, A., Orive, G., Hernández, R. M., Molina, J. A., et al. (2010). The effect of encapsulated VEGF-secreting cells on brain amyloid load and behavioral impairment in a mouse model of Alzheimer's disease. Biomaterials 31, 5608-5618. doi: 10.1016/j.biomaterials.2010.03.042

Sweeney, M. D., Kisler, K., Montagne, A., Toga, A. W., and Zlokovic, B. V. (2018). The role of brain vasculature in neurodegenerative disorders. Nat. Neurosci. 21, 1318-1331. doi: 10.1038/s41593-018-0234-x

Thomas, T., Thomas, G., Mclendon, C., Sutton, T., and Mullan, M. (1996). betaAmyloid-mediated vasoactivity and vascular endothelial damage. Nature 380 , 168-171. doi: $10.1038 / 380168 \mathrm{a} 0$

Tietz, S., and Engelhardt, B. (2015). Brain barriers: crosstalk between complex tight junctions and adherens junctions. J. Cell Biol. 209, 493-506. doi: 10.1083/jcb. 201412147

Van Beek, A. H., and Claassen, J. A. (2011). The cerebrovascular role of the cholinergic neural system in Alzheimer's disease. Behav. Brain Res. 221, 537542. doi: $10.1016 /$ j.bbr.2009.12.047

Vinters, H. V. (2015). Emerging concepts in Alzheimer's disease. Annu. Rev. Pathol. $10,291-319$. 
Wan, W., Cao, L., Liu, L., Zhang, C., Kalionis, B., Tai, X., et al. (2015). Abeta(1-42) oligomer-induced leakage in an in vitro blood-brain barrier model is associated with up-regulation of RAGE and metalloproteinases, and down-regulation of tight junction scaffold proteins. J. Neurochem. 134, 382-393. doi: 10.1111/jnc. 13122

Whitfield, J. F. (2007). The road to LOAD: late-onset Alzheimer's disease and a possible way to block it. Expert Opin. Ther. Targets 11, 1257-1260. doi: 10.1517/ 14728222.11.10.1257

Winkler, E. A., Bell, R. D., and Zlokovic, B. V. (2011). Central nervous system pericytes in health and disease. Nat. Neurosci. 14, 1398-1405. doi: 10.1038/nn. 2946

Yamazaki, Y., and Kanekiyo, T. (2017). Blood-brain barrier dysfunction and the pathogenesis of Alzheimer's Disease. Int. J. Mol. Sci. 18:e18091965.

Yan, S. F., Ramasamy, R., and Schmidt, A. M. (2010). The RAGE axis: a fundamental mechanism signaling danger to the vulnerable vasculature. Circ. Res. 106, 842-853. doi: 10.1161/circresaha.109.212217

Zenaro, E., Piacentino, G., and Constantin, G. (2017). The blood-brain barrier in Alzheimer's disease. Neurobiol. Dis. 107, 41-56.

Zetterberg, H., Mörtberg, E., Song, L., Chang, L., Provuncher, G. K., Patel, P. P., et al. (2011). Hypoxia due to cardiac arrest induces a time-dependent increase in serum amyloid $\beta$ levels in humans. PLoS One 6:e028263. doi: 10.1371/journal. pone.00028263

Zhang, S., Zhi, Y., Li, F., Huang, S., Gao, H., Han, Z., et al. (2018). Transplantation of in vitro cultured endothelial progenitor cells repairs the blood-brain barrier and improves cognitive function of APP/PS1 transgenic AD mice. J. Neurol. Sci. 387, 6-15. doi: 10.1016/j.jns.2018. 01.019
Zhang, X., Zhou, K., Wang, R., Cui, J., Lipton, S. A., Liao, F.-F., et al. (2007). Hypoxia-inducible factor 1alpha (HIF-1alpha)-mediated hypoxia increases BACE1 expression and beta-amyloid generation. J. Biol. Chem. 282, 1087310880. doi: 10.1074/jbc.m608856200

Zhong, Z., Deane, R., Ali, Z., Parisi, M., Shapovalov, Y., O’banion, M. K., et al. (2008). ALS-causing SOD1 mutants generate vascular changes prior to motor neuron degeneration. Nat. Neurosci. 11, 420-422. doi: 10.1038/nn2073

Zipser, B. D., Johanson, C. E., Gonzalez, L., Berzin, T. M., Tavares, R., Hulette, C. M., et al. (2007). Microvascular injury and blood-brain barrier leakage in Alzheimer's disease. Neurobiol. Aging 28, 977-986.

Zlokovic, B. V. (2008). The blood-brain barrier in health and chronic neurodegenerative disorders. Neuron 57, 178-201. doi: 10.1016/j.neuron.2008. 01.003

Zlokovic, B. V. (2011). Neurovascular pathways to neurodegeneration in Alzheimer's disease and other disorders. Nat. Rev. Neurosci. 12, 723-738. doi: $10.1038 / \mathrm{nrn} 3114$

Conflict of Interest: The authors declare that the research was conducted in the absence of any commercial or financial relationships that could be construed as a potential conflict of interest.

Copyright $(2020 \mathrm{Yu}$, Ji and Shao. This is an open-access article distributed under the terms of the Creative Commons Attribution License (CC BY). The use, distribution or reproduction in other forums is permitted, provided the original author(s) and the copyright owner(s) are credited and that the original publication in this journal is cited, in accordance with accepted academic practice. No use, distribution or reproduction is permitted which does not comply with these terms. 